\title{
Distal pancreatectomy outcomes: Perspectives from a community-based teaching institution
}

\author{
Muhammad Umair Bashir ${ }^{1}$, Apostolos Kandilis ${ }^{1}$, Nancy M. Jackson ${ }^{2}$, \\ Janak A. Parikh ${ }^{1}$, and Michael J. Jacobs ${ }^{1}$

\begin{abstract}
Departments of ${ }^{1}$ Surgery and ${ }^{2}$ Research, Ascension Providence and Providence Park Hospitals, Michigan State University College of Human Medicine, Southfield, MI, USA
\end{abstract}

\begin{abstract}
Backgrounds/Aims: Distal pancreatic resections are intricate operations with potential for significant morbidity; there is controversy surrounding the appropriate setting regarding surgeon/hospital volume. We report our distal pancreatectomy experience from a community-based teaching hospital. Methods: This study includes all patients who underwent laparoscopic distal pancreatectomy (LDP) and open distal pancreatectomy (ODP) for benign and malignant lesions between June 2004 and October 2017. Both groups were compared for perioperative characteristics, parenchymal resection technique, and outcomes. Results: 138 patients underwent distal pancreatectomy during this time. The distribution of LDP and ODP was 68 and 70 respectively. Operative time (146 vs. $174 \mathrm{~min}$ ), blood loss (139 vs. $395 \mathrm{ml}$ ) and mean length of stay (4.8 vs. 8.0 days) were significantly lower in the laparoscopic group. The 30 -day Clavien Grade $2 / 3$ morbidity rate was $13.7 \%$ (19/138) and the incidence of Grade B/C pancreatic fistula was $6.5 \%$ (9/138), with no difference between ODP and LDP. 30-day mortality was $0.7 \%$ (1/138). 61/138 resections had a malignancy on final pathology. ODP mean tumor diameter was greater $(6.4 \mathrm{~cm}$ vs. $2.9 \mathrm{~cm})$, but there was no significant difference in the mean number of harvested nodes (8.6 vs. 7.4). The cost of hospitalization, including readmissions and surgery was significantly lower for LDP (\$7558 vs. \$11610). Conclusions: This series of distal pancreatectomies indicates a shorter hospital stay, less operative blood loss and reduced cost in the LDP group, and comparable morbidity and oncologic outcomes between LDP and ODP. It highlights the feasibility and safety of these complex surgeries in a community setting. (Ann Hepatobiliary Pancreat Surg 2020;24:156-161)
\end{abstract}

Key Words: Distal pancreatectomy; Laparoscopic pancreatectomy; Open pancreatectomy; Community hospital

\section{INTRODUCTION}

Pancreatic resections are intricate operations with the potential for significant morbidity. ${ }^{1}$ Open distal pancreatectomy (ODP) was traditionally considered the standard operation for pancreatic body and tail pathology. Advances in surgical technology have made minimally invasive pancreatic surgery, such as laparoscopic distal pancreatectomy (LDP), a safe and feasible alternative to open surgery. Several reports have highlighted the role of laparoscopic distal pancreatectomy in reducing operative morbidity and enhanced recovery. ${ }^{1-4}$ Also, as complex pancreatic surgery continues to undergo centralization to high volume centers, the role of the community-based hepatobiliary and pancreatic programs needs to be elucidated. The objective of this study was to report our experience with both ODP and LDP in a community-based, academic affiliated, teaching hospital.

\section{MATERIALS AND METHODS}

A retrospective comparative study was performed on all patients who underwent LDP and ODP for both benign and malignant pancreatic pathology between June 2004 and October 2017. The study was approved by the Ascension Providence Hospital Institution Review Board (IRB\# 1352673-1). Patients were selected from the institution database and were included if they had a distal pancreatec-

Received: October 15, 2019; Revised: March 19, 2020; Accepted: March 19, 2020

Corresponding author: Muhammad Umair Bashir

Department of Surgery, Ascension Providence and Providence Park Hospitals, Michigan State University College of Human Medicine, 16001 W Nine Mile road, Southfield, MI 48075, USA

Tel: +1775-777-1729, Fax: +1775-753-7866, E-mail: umair2581@gmail.com

Copyright (C) 2020 by The Korean Association of Hepato-Biliary-Pancreatic Surgery

This is an Open Access article distributed under the terms of the Creative Commons Attribution Non-Commercial License (http://creativecommons.org/ licenses/by-nc/4.0) which permits unrestricted non-commercial use, distribution, and reproduction in any medium, provided the original work is properly cited. Annals of Hepato-Biliary-Pancreatic Surgery • pISSN: 2508-5778 - eISSN: 2508-5859 
tomy. Procedures with incomplete information or missing data were excluded. All pancreatic resections were performed within the same hospital system, which is comprised of two campuses with a total of 654 beds. The surgical program is a community-based, academic affiliated, teaching hospital with a residency program that includes a Hepatobiliary and Pancreas (HPB) Fellowship Program since 2013, a critical care unit with 24-hour coverage, and a Level II trauma designation. There is a dedicated hepatobiliary service comprising two HPB trained surgeons.

A total of 138 patients were included in the final analysis. Electronic medical records were individually queried to collect patient demographics, operative variables, and information pertaining to postoperative outcomes that included costs. Pathologic information was obtained for all the distal pancreatectomy patients. Intraoperative variables included: Operative approach (laparoscopic/robotic vs. open); Operative time (min); EBL; Additional organs resection; Type of device used for pancreatic parenchymal resection (stapler, electrocautery, scalpel); Technique of distal pancreas resection for cases with splenectomy (en bloc with splenic vessels vs. separate ligation); and type of resection line reinforcement (sutures, glue, tissue patches). Outcomes included: 30- and 90-day postoperative morbidity; Mortality; Clavien-Dindo classification. ${ }^{5}$ Hospital records were queried to obtain a detailed cost analysis.

SPSS version 23 (IBM Corporation) was used for statistical analysis of the data.

The two groups were compared with Chi-Square and Fisher's Exact tests for discreet variables and the Student's t-test for continuous variables. A $p$-value of less than 0.05

Table 1. Patients' characteristics

\begin{tabular}{|c|c|c|c|}
\hline \multirow{2}{*}{$\begin{array}{c}\text { Patients' } \\
\text { characteristics }\end{array}$} & \multicolumn{2}{|c|}{ Surgical approach } & \multirow[b]{2}{*}{$p$-value } \\
\hline & $\begin{array}{c}\text { LDP } \\
(\mathrm{n}=68)\end{array}$ & $\begin{array}{c}\text { ODP } \\
(\mathrm{n}=70)\end{array}$ & \\
\hline Mean age (y) & 61.3 & 61.7 & 0.87 \\
\hline Gender (female/male) & $46 / 22$ & $46 / 24$ & 0.86 \\
\hline \multicolumn{4}{|l|}{ Comorbidities } \\
\hline Diabetes & 23 & 21 & 0.71 \\
\hline COPD & 6 & 6 & 1 \\
\hline CAD & 8 & 13 & 0.35 \\
\hline Cigarette smoking & 15 & 23 & 0.18 \\
\hline Chronic pancreatitis & 13 & 14 & 0.83 \\
\hline
\end{tabular}

LDP, laparoscopic distal pancreatectomy; ODP, open distal pancreatectomy was considered statistically significant.

\section{RESULTS}

\section{Demographics}

A total of 138 patients underwent distal pancreatectomy between June 2004 and October 2017. Patient characteristics and demographics are presented in Table 1. Comorbidity assessment included diabetes, a history of coronary artery disease (CAD) and/or chronic obstructive pulmonary disease (COPD), smoking status, and a preoperative diagnosis of chronic pancreatitis. Mean age and gender distribution were comparable between the LDP and ODP groups.

\section{Operative/Technical characteristics}

Operative data is presented in Table 2. The distribution of LDP and ODP was 68 and 70, respectively. The mean operative time, EBL, and average length of stay was significantly lower in the LDP group (Table 2). Multivisceral resections other than a splenectomy were performed in $34 / 138$ patients $(24.6 \%)$ to enable an en bloc resection for a tumor. The ODP group had a higher proportion of mul-

Table 2. Perioperative characteristics

\begin{tabular}{lccc}
\hline \multirow{2}{*}{$\begin{array}{c}\text { Perioperative } \\
\text { characteristics }\end{array}$} & $\begin{array}{c}\text { SDP } \\
\text { LDical }\end{array}$ & $\begin{array}{c}\text { Opproach } \\
(\mathrm{n}=68)\end{array}$ & \\
\cline { 2 - 3 }$(\mathrm{n}=70)$ & \\
\hline Operative time (min) & 146 & 174 & 0.004 \\
Estimated blood loss (ml) & 139 & 395 & 0.001 \\
Average length of stay & 4.8 & 8 & 0.001 \\
(days) & & & \\
Spleen preservation & 8 & 5 & 0.4 \\
Multi visceral resection & 9 & 25 & 0.003 \\
Splenic vessel ligation & & & \\
En bloc & 34 & 18 & \\
Separately & 34 & 52 & 0.005 \\
Device for transection & & & \\
Stapler & 66 & 58 & \\
Electrocautery/scalpel & 2 & 9 & 0.03 \\
Transection line & & & \\
reinforcement & & & \\
$\quad$ Yes & 47 & 55 & \\
$\quad$ No & 21 & 15 & 0.25 \\
Cost (including & $\$ 7,558.00$ & $\$ 11,610.0$ & 0.001 \\
readmission costs) & & & \\
\hline
\end{tabular}

LDP, laparoscopic distal pancreatectomy; ODP, open distal pancreatectomy 
tivisceral resections $(\mathrm{n}=25(35 \%) ; p<0.01)$. Overall, the spleen was preserved in 13 patients $(9.4 \%)$, with no significant difference in the splenic preservation rate between the two groups.

Our program has previously reported the technique of stapled en bloc ligation of the splenic vessels along with the distal pancreas for non-spleen preserving distal pancreatectomies. ${ }^{6}$ In this study, the splenic vessels were stapled along with the distal pancreas in 52/138 patients (37\%), while the vessels were dissected and separately ligated in $86 / 138(67 \%)$ of patients, with a higher proportion of such dissections in the open group $(\mathrm{n}=52 ; p<0.01)$. Further, subgroup analysis revealed a significantly lower blood loss with en bloc ligation/resection technique $(195 \mathrm{ml}$ vs $314 \mathrm{ml}, p<0.05)$.

The EndoGIA (Medtronic) stapler was the device used for parenchymal resection in the majority of the cases $(n=124)$. The resection line was routinely reinforced $(\mathrm{n}=102,74 \%)$. Non-absorbable monofilament suture with over sewing of the pancreatic duct and staple line was the most common method of reinforcement. Tissue flaps, such as omental or falciform flaps were performed when feasible and fibrin glue was used in select cases. Electrosurgical energy devices were not used to divide the pancreatic parenchyma.

\section{Morbidity}

Postoperative complications are shown in Table 3. The Clavien 2 and 3 morbidity rate (based on 30-day outcomes) was $13.7 \%$; the overall incidence of clinically fistula (Grade B/C) ${ }^{7}$ was $6.5 \%(9 / 138)$, with no significant difference between the LDP and ODP groups. The 30-day and 90-day mortality was nil and no patients required

Table 3. Postoperative complications

\begin{tabular}{cccc}
\hline \multirow{2}{*}{$\begin{array}{c}\text { Postoperative } \\
\text { complications }\end{array}$} & \multicolumn{2}{c}{ Surgical approach } & \\
\cline { 2 - 3 } & LDP & ODP & \\
\hline $\begin{array}{c}\text { Clavien Grade 1 } \\
\text { complications }\end{array}$ & 1 & 2 & \\
$\begin{array}{c}\text { Clavien Grade 2\&3 } \\
\text { complications }\end{array}$ & 10 & 9 & 0.45 \\
$\begin{array}{c}\text { Pancreatic fistula } \\
\text { (Grade B/C) }\end{array}$ & 6 & 3 & 0.32 \\
\hline
\end{tabular}

LDP, laparoscopic distal pancreatectomy; ODP, open distal pancreatectomy reoperation.

\section{Cost}

Cost analysis between the LDP and ODP groups revealed a similar mean procedural cost: $\$ 3442$ vs. \$3384, $p=0.78$. The procedural cost included surgery and anesthesia-related expenses. However, the overall cost of hospitalization (including readmissions) was significantly higher for the ODP group (\$11,610 vs. $\$ 7,558 ; p<0.01)$.

\section{Pathology}

The final pathology was comparable between the two groups (Table 4). The mean tumor diameter was significantly greater for ODP (6.4 cm vs. $2.9 \mathrm{~cm} ; p<0.01)$, but there was no significant difference in the mean number of harvested nodes between the two groups.

\section{DISCUSSION}

Pancreatic resection has evolved to incorporate an increasing number of minimally invasive approaches. Cuschier ${ }^{8}$ first described minimally invasive pancreatectomy in 1994, and the first laparoscopic distal pancreatectomy was performed by Gagner et al. ${ }^{9}$ in 1996. Contemporary studies have highlighted a reduction in intraoperative blood loss, blood transfusions, wound complications and a decrease in the overall length of stay with minimally invasive distal pancreatectomies. ${ }^{1,2,10,11}$ DiNorcia et al. ${ }^{10}$ reported their audit of 360 patients who underwent a distal

Table 4. Surgical pathology

\begin{tabular}{lccc}
\hline \multirow{2}{*}{$\begin{array}{c}\text { Surgical } \\
\text { pathology }\end{array}$} & \multicolumn{3}{c}{ Surgical approach } \\
\cline { 2 - 3 } & LDP & ODP & \\
& 16 & 24 & 0.27 \\
Pancreatic adenocarcinoma & 14 & 7 & 0.06 \\
$\begin{array}{l}\text { Neuroendocrine } \\
\text { Intraductal papillary mucinous }\end{array}$ & 13 & 9 & 0.17 \\
$\quad$ neoplasm (IPMN) & & & \\
Mucinous cystic neoplasm & 8 & 3 & 0.13 \\
$\quad$ MCN) & & & \\
Serous cystic neoplasm (SCN) & 6 & 4 & 0.53 \\
Chronic pancreatitis & 10 & 12 & 0.82 \\
Other & 3 & 9 & 0.13 \\
Mean tumor dimension (cm) & 2.9 & 6.4 & 0.001 \\
Mean number of nodes harvested & 7.4 & 8.6 & 0.38 \\
\hline
\end{tabular}

LDP, laparoscopic distal pancreatectomy; ODP, open distal pancreatectomy 
pancreatectomy for both benign and malignant pancreatic disease: the LDP patients had fewer overall complications than ODP patients, with a quicker recovery and shorter stay. Adam et al. ${ }^{12}$ evaluated 1733 cases of distal pancreatectomy and reported a reduced hospital stay with comparable short-term oncological outcomes between the open and minimally invasive group, which included both robotic and laparoscopic pancreatectomies. Finally, a review of pancreatic surgery by Postlewit and Kooby ${ }^{13}$ affirmed that minimally invasive distal pancreatectomy is safe and effective for appropriately selected patients with pancreatic ductal adenocarcinoma. The LEOPARD trial has validated these findings in a prospective randomized setting. ${ }^{11,14}$ However, most minimally invasive pancreatic surgical outcomes data is from high volume expert centers, ${ }^{15}$ despite a significant number of pancreatectomies being performed in the community setting. ${ }^{16,17}$ Our retrospective study from a community setting reports a statistically significant decrease in the operative time, blood loss, and length of stay in the laparoscopic group compared to the open cohort.

Several techniques for pancreatic parenchymal resection and splenic vessel ligation have been reported in the literature. ${ }^{18,19}$ We perform a stapled en bloc resection of the distal pancreas simultaneously with the splenic vessels with an EndoGIA stapler (Medtronic). We have previously reported that this technique does not increase the risk of pancreatic leak or hemorrhage. ${ }^{6}$ Our current analyses indicate that en bloc resection of the distal pancreas along with the splenic vessels is associated with a reduced blood loss in both open and laparoscopic distal pancreatectomy, although the technique was most commonly used in the laparoscopic group in this cohort of patients. The overall splenic preservation rate in our study was 9.4\%; the splenic preservation rate in LDP group was $11.7 \%$ while it was $7.1 \%$ in the open group. When compared to the literature, splenic preservation rates range from $15.5-44.2 \%$ in the laparoscopic group compared to $5.7-15.6 \%$ in open pancreatectomy groups. ${ }^{20}$ Most metaanalyses have shown a higher splenic preservation rate with minimally invasive pancreatectomy, likely as result of a magnified view of the splenic hilum during video assisted surgery. ${ }^{20,21}$

Minimally invasive pancreatectomy is considered to be at least non-inferior to conventional open pancreatectomy in terms of oncologic margins and lymph node retrieval for distal pancreatic tumors. ${ }^{4,22-24}$ The results reported in literature are likely confounded by size and type of the distal pancreatic tumor, whereby larger tumors were more likely to undergo an open resection. Our results indicate the same finding, i.e.: the tumor size was significantly smaller in the laparoscopic group and there was higher percentage (albeit not significant) of adenocarcinoma in the open cohort. Surgeon judgment, experience, patient factors, and tumor size may all play a role in the decision to perform one technique over the other. Again, we found no significant difference in the number of harvested nodes and negative resection margins. Overall, there was no significant difference in the pathological characteristics between the LDP and ODP groups. Therefore, when technically feasible we propose that LDP should be offered as the primary therapy for distal pancreatic neoplasia.

We report a similar general complication rate in both groups, including the frequency of clinically significant pancreatic fistula. The major complication and pancreatic fistula rates have been respectively reported as $8-38 \%$ and $11-39 \%$ for distal pancreatectomy. ${ }^{25-28}$ In addition to the variable definitions of postoperative pancreatic fistula, there remains conflicting data regarding the impact of technique and type of pancreatic parenchymal resection line reinforcement and stump closure. ${ }^{29,30}$ A meta-analysis failed to draw firm conclusions on the optimal method of stump closure, although there was a trend towards favoring stapled closure. ${ }^{30}$ Some authors have indicated that specific ligation of the pancreatic duct is an important factor in reducing the incidence of pancreatic fistula. We report an overall pancreatic fistula rate of $6.5 \%$ based on the International Study Group for Pancreatic Fistula (ISGPF) definition of clinically significant Grade B/C fistulas. ${ }^{7}$ Our data did not reveal any preoperative risk factors for a postoperative pancreatic fistula (POPF), including comorbidity profile, smoking status, and a pre-procedure diagnosis of chronic pancreatitis in either of the groups. Furthermore, there was no difference in POPF rates based on the technique of parenchymal resection and type of resection line reinforcement; although an overwhelming number involved the use of the tri-staple EndoGIA (Medtronic) for resection. Finally, the low overall POPF of $6.5 \%$ likely contributed to the lack of any meaningful differences during ad-hoc analysis between 
the subgroups in our cohort of patients. An important factor identified in this regard was the gradual closure of the tri-staple GIA stapler over the course of about a minute during our stapled resections, as previously suggested by Asbun and Stauffer. ${ }^{31}$ Also the stapler cartridge height was routinely adjusted (based on the color coding to indicate various heights) based on the firmness/thickness of the pancreatic tissue. Our study did not retain the data on staple height use per case simply because of variability and the need to exercise judgment per case. Typically, soft pancreas required shorter heights and dense pancreas required larger load heights.

Minimally invasive approaches for distal pancreatectomy are often assumed to be more expensive than open surgery because of the need for expensive surgical equipment and prolonged operations. A few studies have negated the argument of $\operatorname{cost}^{32,33}$ and our study reports a similar procedural cost between the two groups. An important point to note is that a significantly lower overall hospitalization cost was identified for the LDP group, even with readmission.

The appropriate setting for pancreatic surgery has been the topic of much controversy. ${ }^{16,17,34,35}$ The surgical care of patients with pancreatic pathology requires dedicated hospital resources and current evidence suggests that hospitals with a higher annual volume of pancreatic operations have improved short- and long-term outcomes. ${ }^{36,37}$ Most would agree that regionalization of pancreatic surgery is well underway, but these trends fail to take into account regional health care disparity, patient and provider preference for local care, insurance dilemmas, and lack of access for minority groups to tertiary centers, to name a few. Also, readmissions may occur at the local level and may not be accounted for in the larger tertiary centers data. Additionally, hospital volume might not correlate with surgeon volume and vice versa. For example, some proficient surgeons may opt to practice in community-based centers, especially since the advent of HPB fellowships has produced more highly trained HPB surgeon graduates that will likely continue to deploy into the community. Nonetheless, we do not intend to debate reports that highlight positive outcomes based on hospital status and volume. We concur with others findings that this specialization can be carried out in the community setting with minimal LOS, morbidity, and mortality. ${ }^{34}$ We support that hospital volume and dedicated HPB services translate into superior outcomes, regardless of hospital designation. We acknowledge that this study has inherent limitations from its retrospective nature, even though the data has been collected prospectively in a hospital HPB database.

Our retrospective appraisal indicates that complex distal pancreatic resections, both LDP and ODP, can be safely performed in the community setting within the confines of a dedicated and well-constructed HPB program. Furthermore, low pancreatic fistula rates, morbidity, and mortality can be achieved. We suggest, when feasible, en bloc parenchyma and vessel stapled ligation to reduce the rate of postoperative pancreatic fistula and blood loss. We support the judicious use of LDP to reduce overall hospital cost in the community-based teaching institution.

\section{CONFLICT OF INTEREST}

No potential conflict of interest relevant to this article was reported.

\section{ORCID}

Muhammad Umair Bashir:

https://orcid.org/0000-0002-2700-498X

Apostolos Kandilis: https://orcid.org/0000-0003-3192-7653

Nancy M. Jackson:

https://orcid.org/0000-0001-6603-1801

Janak A. Parikh: https://orcid.org/0000-0003-4986-6369

Michael J. Jacobs: https://orcid.org/0000-0003-2401-8697

\section{AUTHOR CONTRIBUTIONS}

Conceptualization: MUB. Data curation: AK. Formal analysis: NMJ. Methodology: AK. Project administration: MJJ. Visualization: JAP. Writing - original draft: MUB. Writing - review \& editing MJJ.

\section{REFERENCES}

1. Damoli I, Butturini G, Ramera M, Paiella S, Marchegiani G, Bassi C. Minimally invasive pancreatic surgery - a review. Wideochir Inne Tech Maloinwazyjne 2015;10:141-149.

2. Matsumoto T, Shibata K, Ohta M, Iwaki K, Uchida H, Yada $\mathrm{K}$, et al. Laparoscopic distal pancreatectomy and open distal pan- 
createctomy: a nonrandomized comparative study. Surg Laparosc Endosc Percutan Tech 2008;18:340-343.

3. Iacobone M, Citton M, Nitti D. Laparoscopic distal pancreatectomy: up-to-date and literature review. World J Gastroenterol 2012;18:5329-5337.

4. Riviere D, Gurusamy KS, Kooby DA, Vollmer CM, Besselink MG, Davidson BR, et al. Laparoscopic versus open distal pancreatectomy for pancreatic cancer. Cochrane Database Syst Rev 2016;4:CD011391.

5. Katayama H, Kurokawa Y, Nakamura K, Ito H, Kanemitsu Y, Masuda N, et al. Extended Clavien-Dindo classification of surgical complications: Japan Clinical Oncology Group postoperative complications criteria. Surg Today 2016;46:668-685.

6. Bendix S, Sathyanarayana SA, Parikh JA, Jacobs MJ. En-bloc resection of the distal pancreas with splenic vessels does not increase risk of pancreatic leak or hematoma. J Am Coll Surg 2015;221(4 Suppl 2):e95.

7. Bassi C, Marchegiani G, Dervenis C, Sarr M, Abu Hilal M, Adham M, et al. The 2016 update of the International Study Group (ISGPS) definition and grading of postoperative pancreatic fistula: 11 years after. Surgery 2017;161:584-591.

8. Cuschieri A. Laparoscopic surgery of the pancreas. J R Coll Surg Edinb 1994;39:178-184.

9. Gagner M, Pomp A, Herrera MF. Early experience with laparoscopic resections of islet cell tumors. Surgery 1996;120:1051-1054.

10. DiNorcia J, Schrope BA, Lee MK, Reavey PL, Rosen SJ, Lee JA, et al. Laparoscopic distal pancreatectomy offers shorter hospital stays with fewer complications. J Gastrointest Surg 2010; 14:1804-1812

11. de Rooij T, van Hilst J, van Santvoort H, Boerma D, van den Boezem P, Daams F, et al. Minimally invasive versus open distal pancreatectomy (LEOPARD): a multicenter patient-blinded randomized controlled trial. Ann Surg 2019;269:2-9.

12. Adam MA, Choudhury K, Goffredo P, Reed SD, Blazer D 3rd, Roman SA, et al. Minimally invasive distal pancreatectomy for cancer: short-term oncologic outcomes in 1,733 patients. World J Surg 2015;39:2564-2572.

13. Postlewait LM, Kooby DA. Laparoscopic distal pancreatectomy for adenocarcinoma: safe and reasonable? J Gastrointest Oncol 2015;6:406-417.

14. van Hilst J, de Rooij T, Bosscha K, Brinkman DJ, van Dieren $\mathrm{S}$, Dijkgraaf $\mathrm{MG}$, et al. Laparoscopic versus open pancreatoduodenectomy for pancreatic or periampullary tumours (LEOPARD-2): a multicentre, patient-blinded, randomised controlled phase 2/3 trial. Lancet Gastroenterol Hepatol 2019;4:199-207.

15. Braga M, Ridolfi C, Balzano G, Castoldi R, Pecorelli N, Di Carlo V. Learning curve for laparoscopic distal pancreatectomy in a high-volume hospital. Updates Surg 2012;64:179-183.

16. Gough BL, Levi S, Sabesan A, Abdel-Misih R, Bennett JJ. Complex distal pancreatectomy outcomes performed at a single institution. Surg Oncol 2018;27:428-432.

17. Hardacre JM, Raigani S, Dumot J. Starting a high-quality pancreatic surgery program at a community hospital. J Gastrointest Surg 2015;19:2178-2182.

18. Cečka F, Jon B, Subrt Z, Ferko A. Surgical technique in distal pancreatectomy: a systematic review of randomized trials. Biomed Res Int 2014;2014:482906

19. Cecka F, Jon B, Ferko A, Subrt Z. [Distal pancreatic resections: indications, surgical technique, and complications]. Rozhl Chir 2009;88:364-367. Czech.

20. Fernández-Cruz L, Orduña D, Cesar-Borges G, López-Boado MA. Distal pancreatectomy: en-bloc splenectomy vs spleen-preserving pancreatectomy. HPB (Oxford) 2005;7:93-98.

21. Tang Y, Tang S, Hu S. The efficacy of spleen-preserving distal pancreatectomy with or without splenic vessel preservation: a meta-analysis. Int J Clin Exp Med 2015;8:17128-17139.

22. Sharpe SM, Talamonti MS, Wang E, Bentrem DJ, Roggin KK, Prinz RA, et al. The laparoscopic approach to distal pancreatectomy for ductal adenocarcinoma results in shorter lengths of stay without compromising oncologic outcomes. Am J Surg 2015;209:557-563.

23. Malleo G, Maggino L, Ferrone CR, Marchegiani G, MinoKenudson M, Capelli P, et al. Number of examined lymph nodes and nodal status assessment in distal pancreatectomy for body/tail ductal adenocarcinoma. Ann Surg 2019;270:1138-1146.

24. Kooby DA, Hawkins WG, Schmidt CM, Weber SM, Bentrem DJ, Gillespie TW, et al. A multicenter analysis of distal pancreatectomy for adenocarcinoma: is laparoscopic resection appropriate? J Am Coll Surg 2010;210:779-785, 786-787.

25. Goh BK, Tan YM, Chung YF, Cheow PC, Ong HS, Chan WH, et al. Critical appraisal of 232 consecutive distal pancreatectomies with emphasis on risk factors, outcome, and management of the postoperative pancreatic fistula: a 21-year experience at a single institution. Arch Surg 2008;143:956-965.

26. Kleeff J, Diener MK, Z'graggen $K$, Hinz U, Wagner $M$, Bachmann J, et al. Distal pancreatectomy: risk factors for surgical failure in 302 consecutive cases. Ann Surg 2007;245:573582.

27. Lillemoe KD, Kaushal S, Cameron JL, Sohn TA, Pitt HA, Yeo CJ. Distal pancreatectomy: indications and outcomes in 235 patients. Ann Surg 1999;229:693-698; discussion 698-700.

28. Parikh PY, Lillemoe KD. Surgical management of pancreatic cancer--distal pancreatectomy. Semin Oncol 2015;42:110-122.

29. Ceppa EP, McCurdy RM, Becerra DC, Kilbane EM, Zyromski NJ, Nakeeb A, et al. Does pancreatic stump closure method influence distal pancreatectomy outcomes? J Gastrointest Surg 2015;19:1449-1456.

30. Tieftrunk E, Demir IE, Schorn S, Sargut M, Scheufele F, Calavrezos L, et al. Pancreatic stump closure techniques and pancreatic fistula formation after distal pancreatectomy: metaanalysis and single-center experience. PLoS One 2018;13: e0197553.

31. Asbun HJ, Stauffer JA. Laparoscopic approach to distal and subtotal pancreatectomy: a clockwise technique. Surg Endosc 2011; 25:2643-2649.

32. Fox AM, Pitzul K, Bhojani F, Kaplan M, Moulton CA, Wei AC, et al. Comparison of outcomes and costs between laparoscopic distal pancreatectomy and open resection at a single center. Surg Endosc 2012;26:1220-1230.

33. Limongelli P, Belli A, Russo G, Cioffi L, D'Agostino A, Fantini C, et al. Laparoscopic and open surgical treatment of left-sided pancreatic lesions: clinical outcomes and cost-effectiveness analysis. Surg Endosc 2012;26:1830-1836.

34. Cunningham JD, O'Donnell N, Starker P. Surgical outcomes following pancreatic resection at a low-volume community hospital: do all patients need to be sent to a regional cancer center? Am J Surg 2009;198:227-230.

35. Ravaioli M, Pinna AD, Francioni G, Montorsi M, Veneroni L, Grazi GL, et al. A partnership model between high- and low-volume hospitals to improve results in hepatobiliary pancreatic surgery. Ann Surg 2014;260:871-875; discussion 875-877.

36. Krautz C, Denz A, Weber GF, Grützmann R. Influence of hospital volume effects and minimum caseload requirements on quality of care in pancreatic surgery in Germany. Visc Med 2017;33: 131-134.

37. Riall TS, Nealon WH, Goodwin JS, Townsend CM Jr, Freeman JL. Outcomes following pancreatic resection: variability among high-volume providers. Surgery 2008;144:133-140. 